\title{
A Novel Enzymatic Method for Preparation and Characterization of Collagen Film from Swim Bladder of Fish Rohu (Labeo rohita)
}

\author{
Ramasamy Sripriya' ${ }^{1}$, Ramadhar Kumar ${ }^{2}$ \\ ${ }^{1}$ Sree Balaji Medical College \& Hospital, Bharath University, Chennai, India \\ ${ }^{2}$ Department of Life Sciences (R\&D), Datt Mediproducts Ltd., Gurgaon, India \\ Email: sree_22@lycos.com, kumar.ramadhar@gmail.com
}

Received 27 October 2015; accepted 21 November 2015; published 24 November 2015

Copyright (C) 2015 by authors and Scientific Research Publishing Inc.

This work is licensed under the Creative Commons Attribution International License (CC BY). http://creativecommons.org/licenses/by/4.0/

(c) (i) Open Access

\begin{abstract}
A novel enzymatic method for extraction and preparation of fish collagen from swim bladder revealed the occurrence of $\alpha, \beta$ and $\gamma$ bands with approximately $12.1 \mathrm{~g} / 100 \mathrm{~g}$ collagen corresponding to $89 \%$ of collagen and thus confirmed the nativity and purity of the fish collagen. FT-IR studies confirmed the retention of all three amide bands of I, II and III, and triple helixcity. UN-crosslinked and UV-crosslinked fish collagen membrane records a very high temperature of helix denaturation at $197^{\circ} \mathrm{C}$ and $215^{\circ} \mathrm{C}$, shrinkage temperature at $50^{\circ} \mathrm{C} \pm 3.2^{\circ} \mathrm{C}$ and $62^{\circ} \mathrm{C} \pm 2.7^{\circ} \mathrm{C}$ and tensile strength at $16.89 \pm 2.5$ and $120.02 \pm 1.0 \mathrm{Kg} / \mathrm{cm}^{2}$ respectively. Fish collagen matrix promoted NIH 3 T3 and L6 cellular growth and proliferation. The study indicates that availability of pure fish collagen could replace bovine collagen in tissue engineering applications.
\end{abstract}

\section{Keywords}

Fish, Swim Bladder Collagen, FT-IR, DSC, Cytocompatibility

\section{Introduction}

Current work deals with a novel enzymatic method for extraction and preparation of fish collagen (FC) from discarded swim bladder of Rohu (Labeo rohita). Rohu is a species of the carp family, found in rivers in South Asia. It is an omnivore. It reaches a maximum length of $2 \mathrm{~m}(6.6 \mathrm{ft})$ and a weight of about $110 \mathrm{~kg}(240 \mathrm{lb})$. It may reach even greater weights in the northern part of Nepal. It is an important aquacultured freshwater species in South Asia. Rohu is very commonly eaten in India, Bangladesh, Nepal, and Pakistan. It is also a very popular food fish in Iraq. 
Collagen is the major protein of connective tissues and the most abundant protein of animal origin [1]-[3]. For industrial purposes, collagen is extracted mainly from skins and bones of cattle and pigs skins and has been widely used in the pharmaceutical, food, healthcare, and cosmetic industries [4] [5]. However, the incidence of diseases such as bovine spongiform encephalopathy (BSE or the popular "mad cow"), and foot and mouth disease has raised concerns about safe use of animal proteins. In addition, the collagen extracted from pigs cannot be used due to religious barriers. For this reason, interest in alternative sources of collagens, which present no health and social risks, has expanded [6]. The other source found for collagen extraction includes skin, bone, fin and scales of fresh water and marine fish, chicken skin, bull frog skin, squid skin, octopus arms and marine sponge [7]-[9]. Among collagen alternatives, fish provided the best source of raw material because of its high availability, no risk of disease transmission, and no religious barriers [10]. Collagens from fish skin or swim bladders which are the waste products in fish processing, may be good substitutes, because of their safety and solubility in neutral salt solutions and dilute acids. Fish collagen is absorbed up to 1.5 times more efficiently into the body, meaning that it has superior bioavailability over bovine or porcine types. Because it is absorbed more efficiently and enters the bloodstream more quickly, it is considered to be the best source of collagen for pharmaceutical applications. Moreover, $75 \%$ of the total weight of fish is discarded as wastes in the form of skins, bones, fins, heads, guts, scales and bladder during processing [11]. If we can reutilize fish processing wastes for the production of collagen-like biomaterials, it may increase the economic value of the fish and fish processing industry. The parts of collagen that are attributed to its immunogenicity namely telopeptides, are eliminated in the process of atelocollagen production. Therefore atelocollagen possesses little immunogenicity [12]. Chemical treatments confer remarkably high strength and stability to collagen matrix but may result in potential cytotoxicity or poor biocompatibility [13], while physical treatment has no cytotoxicity and can provide sufficient stability [14] [15]. The properties of biocompatibility and biodegradation of fish atelocollagen are some of the features that enable the fish collagen to be considered as suitable for the scaffold in tissue engineering, though these phenomena strongly depend on the procedures for crosslinking [16]. If substantial amounts of collagen could be obtained from fish wastes (scale, skin and bone), they would provide an alternative source to bovine collagen in food, cosmetics and biomedical materials.

There are studies that have focused on extraction procedures and characterization of fish-based collagens [5] [9]. In general, the collagen from fish skins and bladder was extracted by soaking them in $\mathrm{NaOH}$ for a minimum duration of 36 hrs with stirring followed by defatting using alcohol solution. After defatting the tissue shall be suspended in acid and enzyme treatment shall be given for 3 days. Finally the fish collagen shall be collected by salt precipitation followed by centrifugation. Therefore the extraction procedures so far reported for collagen extraction was time-consuming taking a minimum of three days for homogenization, two more days for swelling in $\mathrm{NaOH}$ and further a minimum of 2 - 3 days for enzyme treatment which is followed by salt precipitation and centrifugation. In contrast, the extraction method reported in the current study is a simple and novel method developed to extract pure fish collagen from the swim bladder. The pure fish collagen thus obtained was reconstituted in the form of a film and crosslinked by UV irradiation to enhance its thermo-stability. The fish collagen from the swim bladder was further characterized for its physico-chemical and biological properties. Its biological properties are reported for the first time to validate the use of swim bladder extracted collagen application as a biocompatible polymeric material with potential applications as injectables in coating cardiovascular prostheses, support for cell growth and in systems for wound dressing with controlled drug delivery.

\section{Materials and Methods}

\subsection{Extraction of Fish Collagen}

The swim bladders were collected from the fresh water fish Rohu (Labeo rohita) from the local fish market, Chennai, India and they were cut into very fine pieces of random sizes with surgical blade and were suspended overnight in $1 \times$ antibiotic-antimycotic solution (Invitrogen). The fish collagen was thus extracted from the fish swim bladder tissues by following a procedure reported earlier with slight modification [17] (Figure 1). In brief, the pieces of the swim bladder were washed by using $0.3 \% \mathrm{w} / \mathrm{v}$ of Triton X-100, a non-ionic surfactant and were suspended in $0.3 \% \mathrm{w} / \mathrm{w}$ of sodium peroxide solution for $3 \mathrm{hrs}$ followed by washing with Milli Q water. The resultant tissue was further treated with enzyme pepsin $(0.3 \% \mathrm{w} / \mathrm{w}$ in distilled water, $\mathrm{pH} 2.5$ - 3.0) for 10 - $12 \mathrm{hrs}$. Pepsin solubilized fish collagen was further purified by differential salt precipitation ( $\mathrm{NaCl}$ up to $2.5 \mathrm{molL}^{-1}$ ), 


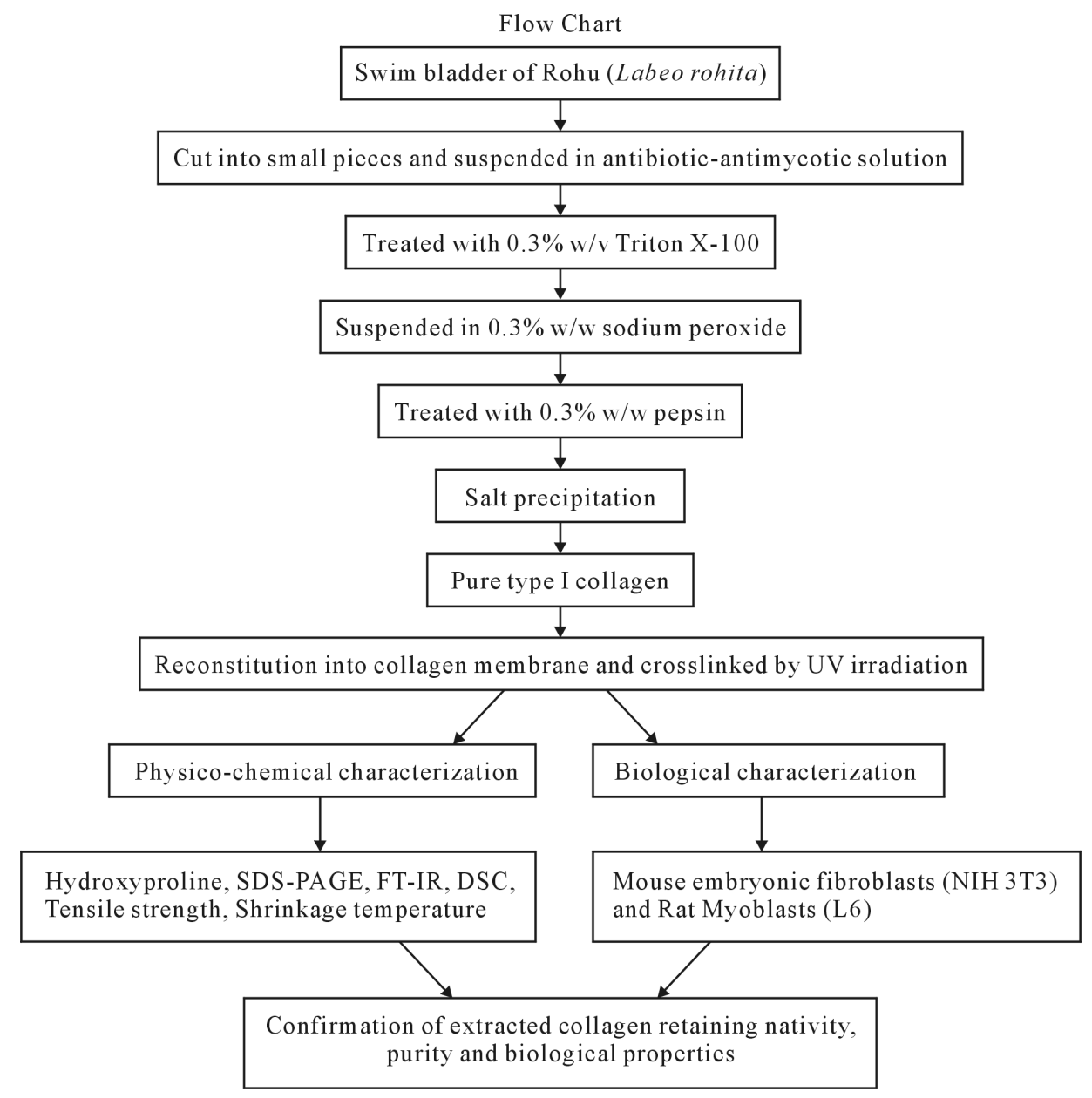

Figure 1. Flow chart of the procedure adopted for extraction of collagen from swim blader.

followed by centrifugation, washing, and lyophilization. The obtained fish collagen (without any further purification) was used for further studies viz. biological, physico-chemical characterization and membrane preparation. All the processes were performed at $4^{\circ} \mathrm{C}$ and used ice cold water wherever required.

\subsection{Preparation of Fish Collagen Film}

The lyophilized fish collagen was dissolved in Millipore water (0.06 $\mu$ s purity) acidified to $\mathrm{pH} 3.5$ using $\mathrm{HCl}$ to get a pure collagen solution. The fish collagen solution was degassed and the clear solution was allowed to dry in Teflon troughs kept in a dust-free chamber and maintained at a temperature of $20^{\circ} \mathrm{C} \pm 5^{\circ} \mathrm{C}$. The fish collagen membranes were crosslinked by UV (NUV) radiation (wavelength, $365 \mathrm{~nm}$ ) for $3 \mathrm{hrs}$.

\subsection{Estimation of Hydroxyproline}

Hydroxyproline of collagen from the swim bladder of the fish collagen was estimated to quantify the collagen purity by using the method of Neuman \& Logan [18] which gives a correlation between collagen content and hydroxyproline content.

\subsection{Gel Electrophoresis}

Sodium dodecyl sulphate-polyacrylamide gel electrophoresis (SDS-PAGE) of the fish collagen samples was done by using Laemmli method [19]. The lyophilized fish collagen samples were dissolved in sample buffer and incubated for 30 minutes at $65^{\circ} \mathrm{C}$. The supernatant sample without residues was loaded onto $8 \%$ separating gel. 
The SDS-PAGE gel was stained with $0.25 \%$ Coomassie brilliant blue R-250 containing 25\% ethanol and 10\% acetic acid and destained with 5\% methanol and 7.5\% acetic acid.

\subsection{Differential Scanning Calorimetric (DSC) Studies}

DSC studies on the fish collagen film were performed by using universal V4.4A TA instruments at $24^{\circ} \mathrm{C}$ and $65 \%$ R. H. Fish collagen membranes (un-crosslinked \& crosslinked) were shielded in aluminium containers and heated at a rate of $10^{\circ} \mathrm{C}$ per minute from $0^{\circ} \mathrm{C}$ to $300^{\circ} \mathrm{C}$ in $\mathrm{N}_{2}$ atmosphere and the thermograms were recorded.

\subsection{Fourier Transform Infrared Spectroscopy (FT-IR) Studies}

Collagen-potassium bromide pellets was prepared by powdering lyophilized fish collagen with potassium bromide and further subjected to FTIR studies by using a Thermo Nicolet avatar 320 FTIR spectrometer (Nicolet Instrument Con., Madison, WI). The spectra of the fish collagen were recorded in the range of 400 to $4000 \mathrm{~cm}^{-1}$ at $25^{\circ} \mathrm{C}$.

\subsection{Studies of Shrinkage Temperature}

The shrinkage temperature of the fish collagen membranes was measured in micro shrinkage meter fitted with a field microscope. Fish collagen membrane cut into the size of $1 \mathrm{sq} \cdot \mathrm{cm}$, in distilled water was placed on the wet surface (distilled water) of a micro slide and the temperature of the slide was raised slowly by $1^{\circ} \mathrm{C} / \mathrm{min}$ and the shrinkage of the fish collagen membrane was determined through the microscope. The temperature at which the fish collagen membrane shrinks approximately half to its original size was taken it as the shrinkage temperature.

\subsection{Studies of Tensile Strength}

The fish collagen membrane was cut into $16 \mathrm{~mm}$ dumbbells with $5.15 \mathrm{~mm}$ inner width and immersed in distilled water for $30 \mathrm{~min}$ and the tensile force were applied at an extension rate of $10 \mathrm{~mm} / \mathrm{min}$. The ends of the fish collagen membrane were held by pneumatic grips (40 psi grip pressure) and the tensile strengths of the collagen membranes were tested by Instron series II Automated Materials Testing System.

\subsection{Biological Characterization and Culture of Cell Lines}

Biological characterization of the fish collagen was performed by evaluating the degree of cell proliferation, growth and morphological examinations of mouse embryonic fibroblasts (NIH 3T3) and L6 myocytes cell lines. 3-(4,5-Dimethylthiazol-2-yl)-2,5-diphenyltetrazolium (MTT) assay was performed to evaluate the degree of cell proliferation [20] as viable cells with active metabolism convert MTT into a purple colored formazan product. The quantity of formazan (presumably directly proportional to the number of viable cells) is measured by recording changes in absorbance at $630 \mathrm{~nm}$ using a plate reading spectrophotometer [21]. All cell lines (NIH 3T3 \& L6 myocytes) were obtained from National Centre for Cell Science (NCCS), Pune, India and the cell cultures were maintained in DMEM with 10\% fetal calf serum (FCS) supplemented with penicillin (120 units/ml), streptomycin $(75 \mathrm{mg} / \mathrm{ml})$, gentamycin $(160 \mathrm{mg} / \mathrm{ml})$ and amphotericin $\mathrm{B}(3 \mathrm{mg} / \mathrm{ml})$ at $37^{\circ} \mathrm{C}$ with $5 \% \mathrm{CO}_{2}$.

\subsection{Experimental Design for Cytoproliferative Effects of Collagen Matrix}

The cytoproliferative effects of the fish collagen matrix and polystyrene were determined. Polystyrene cell culture plates were coated with $0.5 \%$ fish collagen solution and dried under a laminar air flow hood followed by UV sterilization. The uncoated wells were used as control. The cells were seeded at the density of $2 \times 10^{4}$ per well and were incubated at $37^{\circ} \mathrm{C}$ in a humidified atmosphere containing $5 \% \mathrm{CO}_{2}$. In all cell culture conditions, the fresh cell culture medium was renewed every day. After 24 and 48 hrs of incubation, the supernatant of each well was replaced with MTT diluted in serum-free medium and the cell culture plates were incubated at $37^{\circ} \mathrm{C}$ for $3 \mathrm{hrs}$. After aspirating the MTT solution, acid isopropanol (0.04 N HCl in isopropanol) was added to each well and pipetted up and down to dissolve all of the dark blue crystals and then left at room temperature for a few minutes to ensure all crystals are dissolved. Finally, absorbance (optical density) was measured at $630 \mathrm{~nm}$ by using a UV spectrophotometer. Each experiment was repeated at least three times. The sets of three wells for the MTT assay were used for each experimental variant. 


\subsection{Statistical Analysis}

The results of the current study are expressed as mean \pm standard error of the mean (SEM). Data obtained from the current study were analysed by student's t-test and differences at the $95 \%$ level were considered to be statistically significant.

\section{Results}

\subsection{Hydroxyproline Content of Fish Collagen}

The hydroxyproline content of the extracted fish collagen protein mass was found to be approximately 12.1 $\mathrm{g} / 100 \mathrm{~g}$ collagen which corresponds to more than $89 \%$ purity of collagen in the extracted mass.

\subsection{Gel Electrophoresis (SDS-PAGE) of Fish Collagen}

The extracted pure fish collagen from swim bladder was characterised by SDS-PAGE (8\%) gel. The electrophoretic pattern of the protein sample of the fish swim bladder (Labeo rohita) is shown in Figure 2. The fish collagen constituted largely of $\alpha$ with a considerable amount of $\beta$ (dimer) and $\gamma$ (trimer) band. Two $\alpha$ bands corresponding to $\alpha_{1}$ and $\alpha_{2}$, which were the unfolding polypeptide chains of the triple helix of the fish collagen.

\subsection{Differential Scanning Calorimetric (DSC) Studies}

Both un-crosslinked and UV crosslinked fish collagen membrane obtained in the current study were analyzed for their thermal stability by DSC for which the samples were heated from $0^{\circ} \mathrm{C}$ to $300^{\circ} \mathrm{C}$ and the thermograms recorded and illustrated (Figure 3 and Figure 4). In the case of un-crosslinked fish collagen, the endothermic peak observed at $84^{\circ} \mathrm{C}$ could be attributed to water loss/evaporation and the occurrence of another peak around $197^{\circ} \mathrm{C}$ reflected the melting temperature of the fish collagen due to helix denaturation (Figure 3) whereas in UV crosslinked fish collagen membrane, the water loss was observed near $110^{\circ} \mathrm{C}$ and helix denaturation occurred around $215^{\circ} \mathrm{C}$ (Figure 4).

\subsection{Fourier Transform Infrared Spectroscopy (FT-IR) Studies of Fish Collagen Matrix}

The FT-IR spectrum (Figure 5) of the fish collagen obtained in the present study showed the presence and retention of all major three amide band viz. I, II, and III at the region of $1636-1661 \mathrm{~cm}^{-1}, 1549-1558 \mathrm{~cm}^{-1}$ and

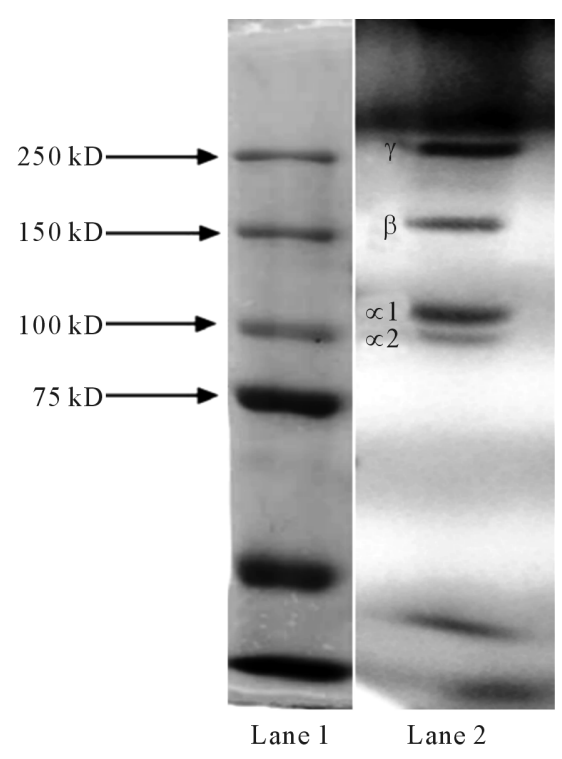

Figure 2. SDS-PAGE electrophoretogram of the fish collagen sample shows the occurrence of band pattern of $\alpha, \beta$ and $\gamma$ isomers. No other major protein bands were observed. 


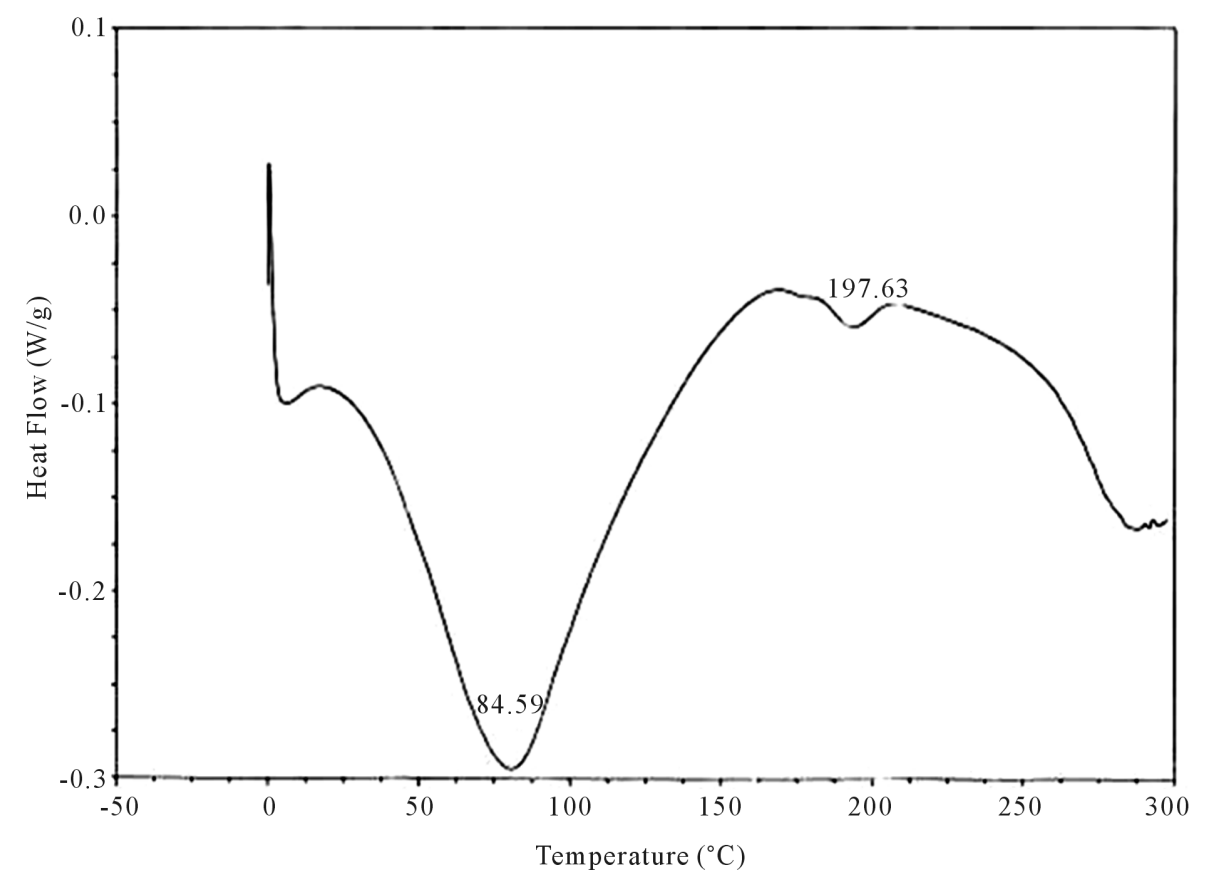

Figure 3. Differential scanning calorimetric scan of fish collagen recorded using calorimeter (DSC 204) with collagen membrane shielded in aluminium containers in the temperature range of $-5^{\circ} \mathrm{C}$ and $200^{\circ} \mathrm{C}$ in the $\mathrm{N}_{2}$ atmosphere is showed in the figure. The DSC scan shows an endothermic peak at $84^{\circ} \mathrm{C}$ attributed to water loss/evaporation. The occurrence of another peak around $197^{\circ} \mathrm{C}$ reflected the melting temperature of the fish collagen due to helix denaturation.

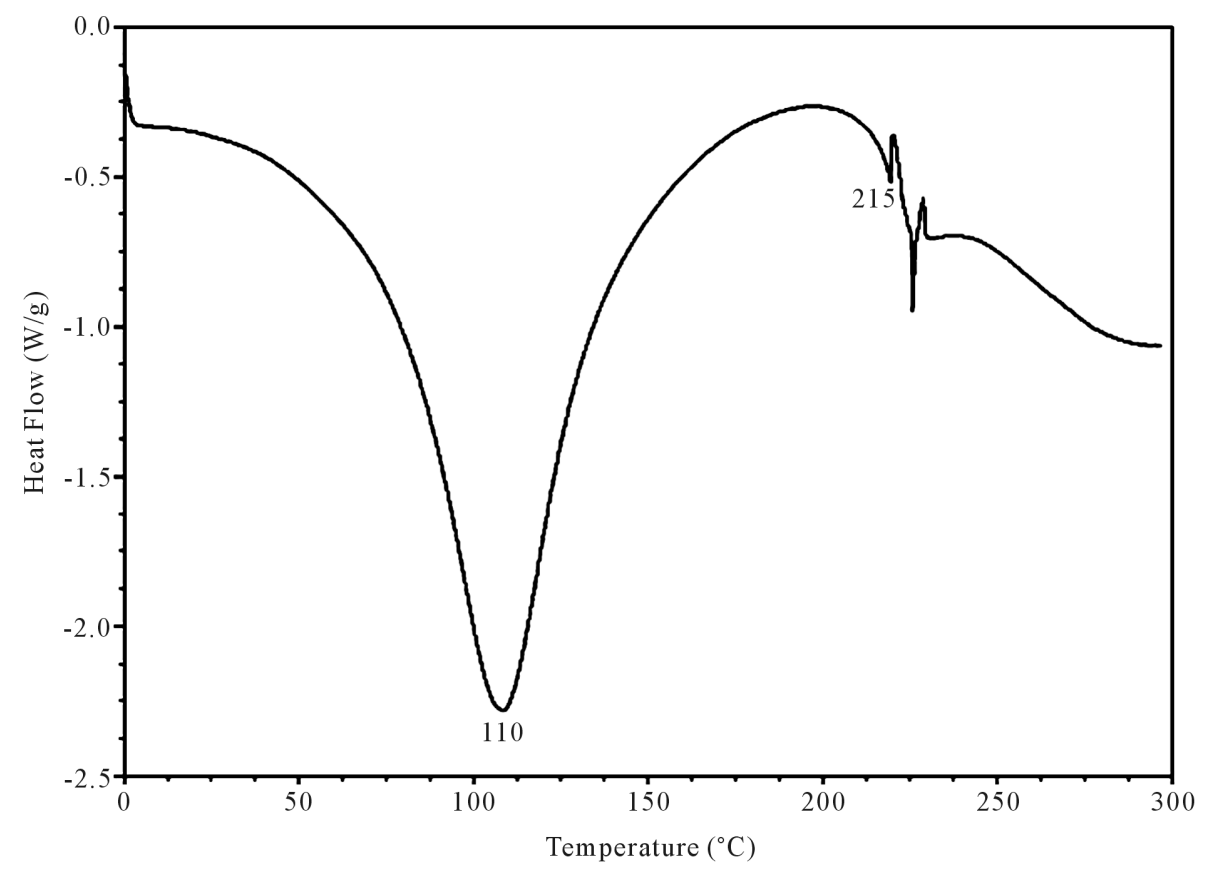

Figure 4. Differential scanning calorimetric Scan of UV-crosslinked fish collagen recorded using calorimeter (DSC 204) with collagen membrane shielded in aluminium containers in the temperature range of $-5^{\circ} \mathrm{C}$ and $200^{\circ} \mathrm{C}$ in the $\mathrm{N}_{2}$ atmosphere is shown in the figure. The DSC scan records endothermic peak at $110^{\circ} \mathrm{C}$ attributed to water loss and helix denaturation around $215^{\circ} \mathrm{C}$. 


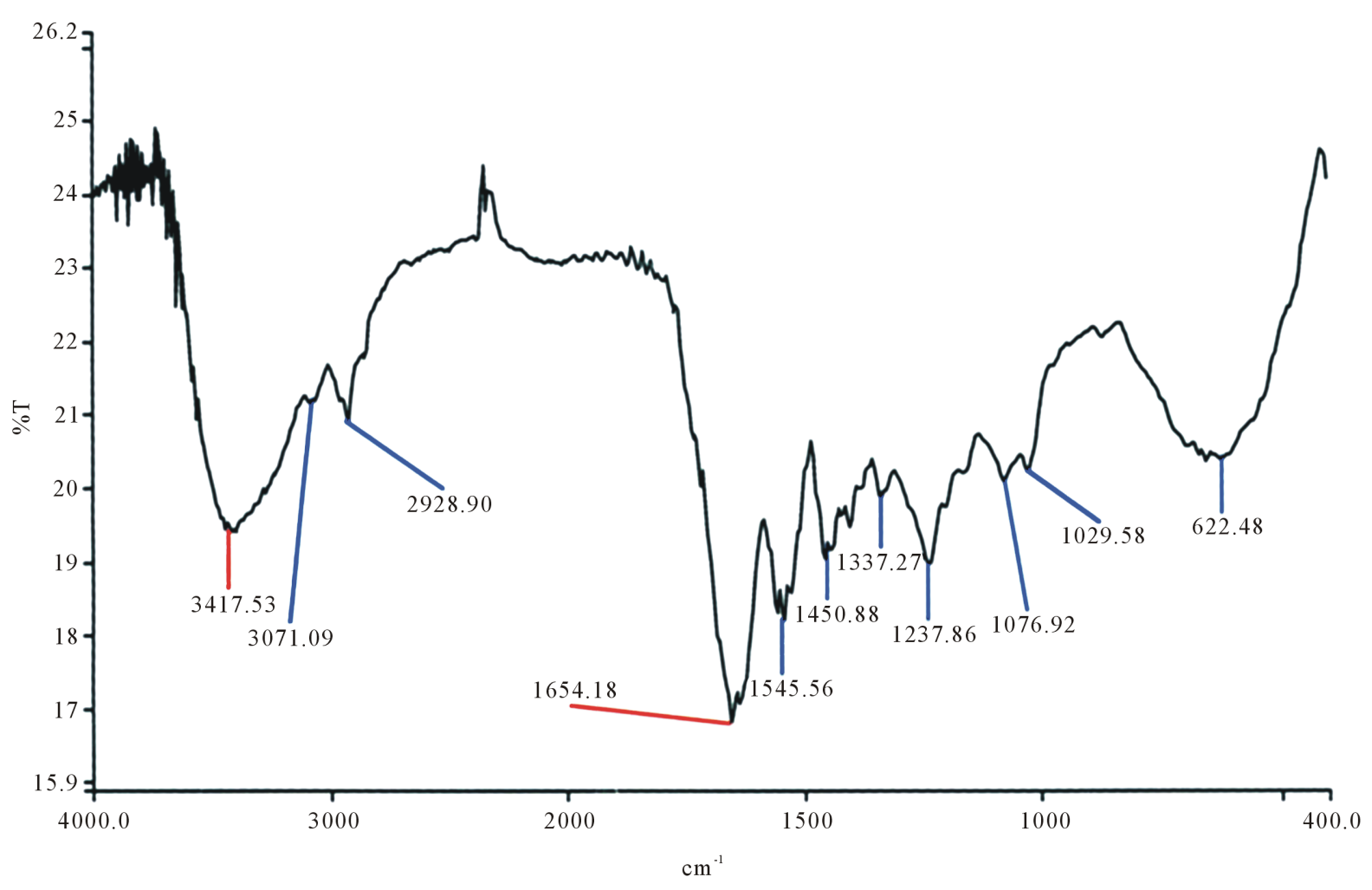

Figure 5. Fourier transform infrared spectrum of fish collagen recorded using collagen films through Nicolet 2DDKB FTIR spectrometer at $25^{\circ} \mathrm{C}$ using OMNIC (Version 6.0) software is shown in the figure. The FT-IR spectra show the secondary structure of the fish collagen proteins as amide I, amide II and amide III band. The ratio of IR absorption intensity between $1237 \mathrm{~cm}^{-1}$ (amide III) and $1450 \mathrm{~cm}^{-1}$ (amide II) band was approximately equal to 1.0, which confirms the triple helical structure of collagen.

$1200-1300 \mathrm{~cm}^{-1}$ which in turn validated the integrity of the proteins in the conformation of the collagen molecules. While the peak situated in the range of $670-640 \mathrm{~cm}^{-1}$ in the fish collagen can be attributed to the C-S stretching vibrations. The protein band occurring close to $1450 \mathrm{~cm}^{-1}$ is probably associated with C-H bending modes and the amide-A band ( $\mathrm{NH}$ stretching), was observed at $3400 \mathrm{~cm}^{-1}$.

\subsection{Shrinkage Temperature Analysis}

The shrinkage temperature of the un-crosslinked fish collagen membrane records at $50^{\circ} \mathrm{C} \pm 3.2^{\circ} \mathrm{C}$ whereas the $\mathrm{UV}$ crosslinked collagen showed shrinkage temperature at $62^{\circ} \mathrm{C} \pm 2.7^{\circ} \mathrm{C}$.

\subsection{Tensile Strength Analysis}

The mean tensile strength of un-crosslinked fish collagen membrane records at $16.89 \pm 2.5 \mathrm{Kg} / \mathrm{cm}^{2}$ whereas, the UV crosslinked fish collagen membrane shows $120.02 \pm 1.0 \mathrm{Kg} / \mathrm{cm}^{2}$ executing the increased strength of the biomaterial fish collagen membrane after crosslinking.

\subsection{Cytoproliferative Effects of Fish Collagen Matrix}

In the present study, we used the mouse embryonic fibroblasts (NIH 3T3) and rat myoblasts (L6) to observe the degree of cellular growth and proliferation on fish collagen matrices and polystyrene surface. Interestingly, we found that the rate of proliferation of both L6 and NIH3T3 was relatively more in comparison to control (Figure 6) with good morphology of cells in the cell culture as observed under a phase contrast inverted microscope (Figure 7). Moreover, L6 myoblasts proliferation and differentiation into myotubes was more pronounced on collagen matrix (data not shown). 


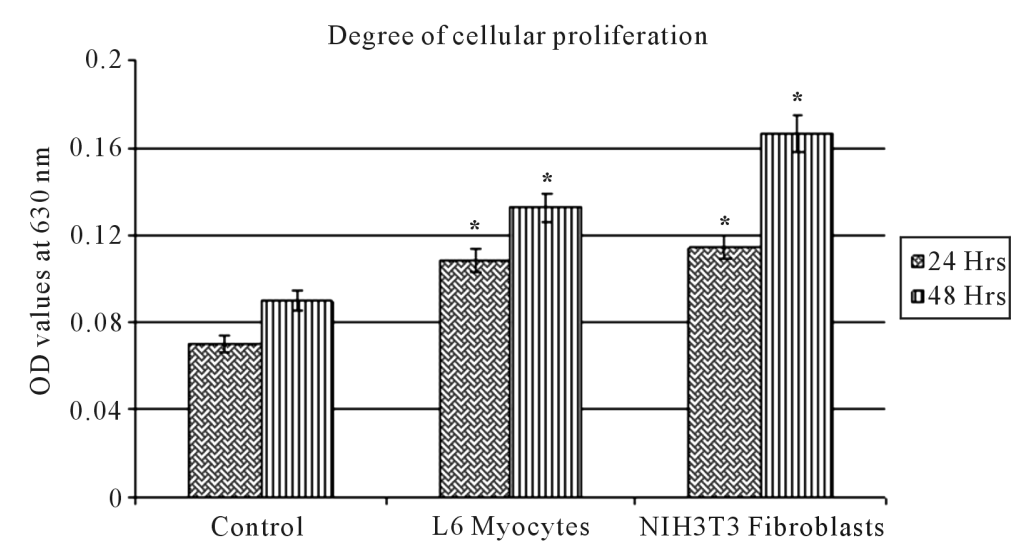

Figure 6. Degree of cellular proliferation of both L6 and NIH3T3 evaluated by MTT assay and results were evaluated after 24 and 48 hrs of incubation as shown in the figure. The rate of proliferation of both L6 and NIH3T3 was relatively more in comparison to control. Bars represent mean \pm SEM of five wells $(p<0.05)$.
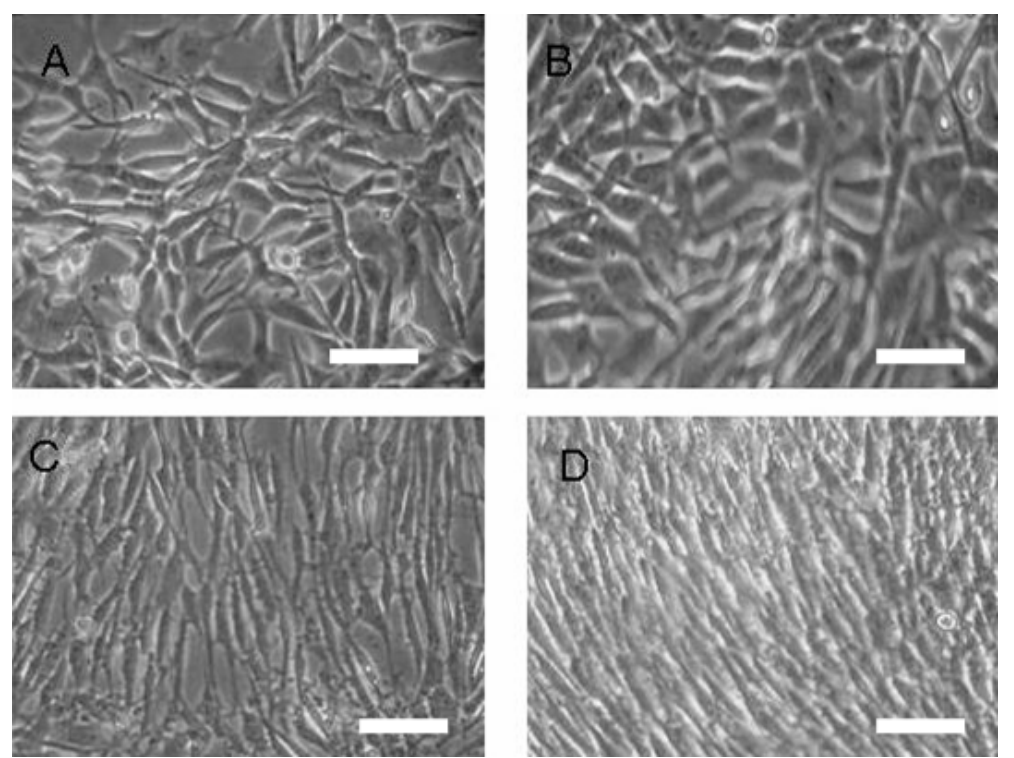

Figure 7. Microscopic images $(\times 200)$ of NIH 3 T3 fibroblasts (A) on polystyrene (control) substratum, (B) on fish collagen substratum; L6 myoblasts (C) on polystyrene substratum, (D) on fish collagen substratum. Cellular proliferation with good morphology of cells in the cell culture as observed under a phase contrast inverted microscope. The scale bar used is $30 \mu \mathrm{m}$.

\section{Discussion}

On the basis of the amino acid analysis of the fish collagen, the quantity of hydroxyproline is present to the extent of $12.8 \mathrm{~g} / 100 \mathrm{~g}$ of collagen [22] or approximately $13 \%$ of its weight [23]. The current study showed hydroxyproline value which is comparable with reported values indicating that the collagen extracted from the fish swim bladder is of high purity. The occurrence of the pattern of $\alpha, \beta$ and $\gamma$ isomers of the fish collagen and no other major protein bands were observed indicating the nativity of the extracted fish collagen. The pattern of $\alpha, \beta$ and $\gamma$ isomers of the fish collagen from the current study compares favourably with the electrophoretic pattern reported earlier [16], for the fish collagen from swim bladder of catfish (Tachysurus maculatus). DSC values obtained in the present study are relatively higher than the DSC values of tropical fishes: i.e. fish collagen from fish such as Arius parkeri (Gurijuba), Cynoscion acoupa (Pescada Amarela) and Cynoscion leiarchus (Pescada 
Branca) showed difference in their denaturation temperature ranging from $65.9^{\circ} \mathrm{C}$ to $74.8^{\circ} \mathrm{C}$ [6]. Thus the increased temperature for water loss in UV crosslinked fish collagen could have been due to tightly bound water molecules with collagen as a result of crosslinking. Swim bladder collagen-chitosan of cat fish records thermal decomposition by thermo gravimetric analysis at $209^{\circ} \mathrm{C}$ for un-crosslinked and $240^{\circ} \mathrm{C}$ for glutraldehyde crosslinked collagen indicating the crosslinking lead to thermo stability [16]. Moreover thermostability of fish collagen from the internal tissues (swim bladders and bones) was slightly higher than that of pepsin solubilized collagen from the external tissues (fins, scales and skins) [24]. Collagen film prepared from bovine serosa registered a denaturation temperature range from $55.23^{\circ} \mathrm{C}$ to $80.55^{\circ} \mathrm{C}$ [25] [26]. Moreover the thermal stability of the fish collagen depends on several factors like physiological temperature of the fish, species to which it belongs and has direct correlation with imino acid (proline and hydroxyproline) content. Triple helical structure of the collagen molecule is more stable with higher imino acid content as these facilitate intra and intermolecular crosslinking [27]. The denaturation of the fish collagen membrane also depends on the factors like solvent used, ionic strength, $\mathrm{pH}$ and humidity. The results of the current study indicated that the extracted fish collagen to exhibit good thermal stability which increased significantly after crosslinking. There are also interesting consequences of variation in denaturation temperature with variation in temperature of their living environment. The deep sea fishes have lower denaturation temperature in comparison to fresh water fish therefore the isolated type I collagen from fish swim bladder may find wide biomedical application due to its high denaturation temperature. FT-IR has been shown to be useful tool for testing unknown biological materials such as fish collagen that might have been altered, and moreover it relies on objective criteria such as changes of the IR absorption frequency and intensity in various functional groups of biological molecules. The usefulness of FT-IR spectroscopy has also been demonstrated by determining the secondary structure of the fish collagen proteins as amide I, amide II and amide III band. The exact frequencies of these stretching vibrations can be noted for amide I which depends upon the strength of the hydrogen bond to the carbonyl oxygen and the environment dictated by the local peptide conformation. Amide A band is almost symmetric, suggesting that the amount of water present in the fish collagen must be low. The ratio of IR absorption intensity between $1237 \mathrm{~cm}^{-1}$ (amide III) and $1450 \mathrm{~cm}^{-1}$ (amide II) band was approximately equal to 1.0, which confirms the triple helical structure of collagen. The measurement of fish collagen shrinkage by a micro-shrinkage apparatus has been shown to be a useful research tool, relating to gross tissue changes to events occurring at the molecular structural level, and the temperature of isotonic contraction (shrinkage temperature) could be used to investigate these molecular changes. Shrinkage of the fish collagen occurs as a result of hydrothermal denaturation of the collagen protein molecules and is monitored with a micro-shrinkage apparatus. Thus the present study has shown that the shrinkage temperature of the fish collagen membrane is also known to be influenced by different factors, most of which appear to be influenced by the number and nature of crosslinking interactions between adjacent polypeptide chains of the protein molecules. The increased strength of the crosslinked fish collagen membrane is due to the UV irradiation that in turn could have promoted bonds formation between free radicals generated on aromatic amino-acid residues as reported by Cooper \& Davidson [28] and Fujimori [29]. The current study has thus confirmed the usefulness of collagen in promoting the proliferation and differentiation of the cells in culture. The use of collagen-based biomaterials has been reported on several occasions in the literature to aid in biomedical implant or as a coating material, wound healing and in reconstructive surgery [30] [31] due to which it occupies prominent position in the field of tissue engineering. Collagen substrates have been shown to influence proliferation, migration, and differentiation of a number of cell types in vitro [32]. The cell proliferation and viability of live cells were measured by the MTT assay which determines the active mitochondrial enzymes present in the viable cell which in turn utilizes the MTT as substrate, converting it to a coloured (Formazan) product. In contrast dead cells does not have the ability to convert MTT into formazan, thus colour formation serves as a useful and convenient marker of only the viable cells. It is a colorimetric assay in which the degree of absorbance of Formazon directly reflects the number of viable cells. Cell attachment, proliferation and differentiation depend on the nature of the matrix and cell type [33] [34].

\section{Conclusion}

The current study has shown the novelty of the preparation method by its retention of nativity, purity, triple helixcity, biocompatibility and very high thermal stability of fish collagen extracted from the swim bladder of fishes which are normally left as waste materials as an alternate source of collagen for industrial purposes. The 
fish collagen extracted by the current novel method resembles in many ways with the more widely studied collagen of mammals in its physico-chemical properties and thus shows potential as a cell substrate, suggesting the possibility of use as a source collagen for pharmaceutical and biomedical application.

\section{Acknowledgements}

The authors Dr. R. Sripriya and Dr. Ramadhar Kumar dedicate this research article to Late Dr. P. K. Sehgal, (Chief Scientist, Central Leather Research Institute), for his valuable guidance, inspiration, coaching and enthusiasm and they gratefully acknowledge the Council of Scientific Research (CSIR) for financial support at the Central Leather Research Institute (CLRI), Chennai 600020, India. We acknowledge Sree Balaji Medical College \& Hospital (SBMCH), Bharath Institute of Higher Education and Research for extending the research facilities to complete the work.

\section{References}

[1] Muyonga, J.H., Cole, C.G.B. and Duodu, K.G. (2004) Characterisation of Acid Soluble Collagen from Skins of Young and Adult Nile Perch (Lates niloticus). Food Chemistry, 85, 81-89. http://dx.doi.org/10.1016/j.foodchem.2003.06.006

[2] Usha, R., Maheshwari, R., Dhathathreyan, A. and Ramasami, T. (2006) Structural Influence of Mono and Polyhydric Alcohols on the Stabilization of Collagen. Colloid Surface B, 48, 101-105. http://dx.doi.org/10.1016/j.colsurfb.2006.01.015

[3] Pinazo, A. (1996) Effect of Surfactant Structure on Diffusion through a Collagen Membrane. Colloid Surface B, 8, 63-72. http://dx.doi.org/10.1016/S0927-7765(96)01306-9

[4] Reid, G., Lam, D., Policova, Z. and Neumann, A.W. (1993) Adhesion of Two Uropathogens to Silicone and Lubricious Catheters: Influence of $\mathrm{pH}$, Urea and Creatinine. Journal of Materials Science: Materials in Medicine, 4, 17-22. http://dx.doi.org/10.1007/bf00122972

[5] Ogawa, M., et al. (2004) Biochemical Properties of Bone and Scale Collagens Isolated from the Subtropical Fish Black Drum (Pogonis cromis) and Sheepshead Seabream (Archosargus probatocephalus). Food Chemistry, 88, 495-501. http://dx.doi.org/10.1016/j.foodchem.2004.02.006

[6] Fernandes, R.M., Couto Neto, R.G., Paschoal, C.W., Rohling, J.H. and Bezerra, C.W. (2008) Collagen Films from Swim Bladders: Preparation Method and Properties. Colloid Surface B, 62, 17-21.

http://dx.doi.org/10.1016/j.colsurfb.2007.09.011

[7] Sadowska, M., Kolodziejska, I. and Niecikowska, C. (2003) Isolation of Collagen from the Skins of Baltic Cod (Gadus morhua). Food Chemistry, 81, 257-262. http://dx.doi.org/10.1016/S0308-8146(02)00420-X

[8] Nagai, T. and Suzuki, N. (2000) Isolation of Collagen from Fish Waste Material—Skin, Bone and Fins. Food Chemistry, 68, 277-281. http://dx.doi.org/10.1016/S0308-8146(99)00188-0

[9] Nagai, T. and Suzuki, N. (2002) Preparation and Partial Characterization of Collagen from Paper Nautilus (Argonauta argo, Linnaeus) Outer Skin. Food Chemistry, 76, 149-153. http://dx.doi.org/10.1016/S0308-8146(01)00255-2

[10] Senaratne, L.S., Park, P.J. and Kim, S.K. (2006) Isolation and Characterization of Collagen from Brown Backed Toadfish (Lagocephalus gloveri) Skin. Bioresource Technology, 97, 191-197. http://dx.doi.org/10.1016/j.biortech.2005.02.024

[11] Shahidi, F. (1994) Seafoods: Chemistry, Processing, Technology and Quality. Blackie Academic and Professional, Glasgow. http://dx.doi.org/10.1007/978-1-4615-2181-5

[12] Sano, A., Maeda, M., Nagahara, S., Ochiya, T., Honma, K., Itoh, H., et al. (2003) Atelocollagen for Protein and Gene Delivery. Advanced Drug Delivery Reviews, 55, 1651-1677. http://dx.doi.org/10.1016/j.addr.2003.08.005

[13] Huang-Lee, L., Cheung, D.T. and Nimni, M.E. (1990) Biochemical Changes and Cytotoxicity Associated with the Degradation of Polymeric Glutaraldehyde Derived Crosslinks. Journal of Biomedical Materials Research, 24, 11851201. http://dx.doi.org/10.1002/jbm.820240905

[14] Koide, M., Osaki, K., Konishi, J., Oyamada, K., Katakura, T., Takahashi, A. and Yoshizato, K. (1993) A New Type of Biomaterial for Artificial Skin: Dehydrothermally Cross-Linked Composites of Fibrillar and Denatured Collagen. Journal of Biomedical Materials Research, 27, 79-84. http://dx.doi.org/10.1002/jbm.820270111

[15] Safandowska, M. and Pietrucha, K. (2013) A New Method of Determination of Collagen Conjugated with Keratin. Autex Research Journal, 13, 37-39. http://dx.doi.org/10.2478/v10304-012-0024-6

[16] Bama, P., Vijayalakshimi, M., Jayasimman, R., Kalaichelvan, P.T., Deccaraman, M. and Sankaranarayanan, S. (2010) Extraction of Collagen from Cat Fish (Tachysurus maculatus) by Pepsin Digestion and Preparation and Characterization of Collagen Chitosan Sheet. International Journal of Pharmacy and Pharmaceutical Sciences, 2, 133-137. 
[17] Sripriya, R., Ahmed, M.R., Sehgal, P.K. and Jayakumar, R. (2003) Influence of Laboratory Ware Related Changes in Conformational and Mechanical Properties of Collagen. Journal of Applied Polymer Science, 87, 2186-2192. http://dx.doi.org/10.1002/app.11651

[18] Neuman, R.E. and Logan, M.A. (1950) Determination of Collagen and Elastin in Tissues. The Journal of Biological Chemistry, 186, 549-556.

[19] Leammli, U.K. (1970) Discontinuous Buffer System for Slab Gel. Nature, 227, 680-681.

[20] Mosmann, T. (1983) Rapid Colorimetric Assay for Cellular Growth and Survival: Application to Proliferation and Cytotoxicity Assays. Journal of Immunological Methods, 65, 55-63. http://dx.doi.org/10.1016/0022-1759(83)90303-4

[21] Marshall, N.J., Goodwin, C.J. and Holt, S.J. (1995) A Critical Assessment of the Use of Microculture Tetrazolium Assays to Measure Cell Growth and Function. Growth Regulation, 5, 69-84.

[22] Spackman, D.H., Stein, W.H. and Moore, S. (1958) Automatic Recording Apparatus for Use in the Chromatography of Amino Acids. Analytical Chemistry, 30, 1190-1205. http://dx.doi.org/10.1021/ac60139a006

[23] Oliver, R.F., Barker, H., Cooke, A. and Grant, R.A. (1982) Dermal Collagen Implants. Biomaterials, 3, 38-40. http://dx.doi.org/10.1016/0142-9612(82)90059-X

[24] Liu, D., Liang, L., Joe, M. and Zhou, R.P. (2012) Extraction and Characterisation of Pepsin-Solubilised Collagen from Fins, Scales, Skins, Bones and Swim Bladders of Bighead Carp (Hypophthalmichthys nobilis). Food Chemistry, 133, 1441-1448. http://dx.doi.org/10.1016/j.foodchem.2012.02.032

[25] Goes, J.D., Figueiro, S.D., de Paiva, J.A.C., de Vasconcelos, I.F. and Sombra, A.S.B. (2002) On the Piezoelectricity of Anionic Collagen Films. Journal of Physics and Chemistry of Solids, 63, 465-470. http://dx.doi.org/10.1016/S0022-3697(01)00161-5

[26] Silva, C.C., Pinheiro, A.G., Thomazini, D., Góes, J.C., Figueiró, S.D., de Paiva, J.A.C. and Sombra, A.S.B. (2001) Effect of the $\mathrm{pH}$ on the Piezoelectric Properties of Collagen Films. Materials Science and Engineering: B, 83, 165-172. http://dx.doi.org/10.1016/S0921-5107(01)00520-7

[27] Wong, D.W.S. (1989) Mechanism and Theory in Food Chemistry. Van Nostrand Reinhold Company, New York.

[28] Cooper, D.R. and Davidson, R.J. (1965) The Effect of Ultraviolet Irradiation on Soluble Collagen. Biochemical Journal, 97, 139-147. http://dx.doi.org/10.1042/bj0970139

[29] Fujimori, E. (1965) UV Light-Induced Change in Collagen Macromolecules. Biopolymers, 3, 115-119. http://dx.doi.org/10.1002/bip.360030202

[30] Singer, A.J. and Clark, R.A. (1999) Cutaneous Wound Healing. The New England Journal of Medicine, 341, 738-746. http://dx.doi.org/10.1056/NEJM199909023411006

[31] Sefton, M.V. and Woodhouse, K.A. (1998) Tissue Engineering. Journal of Cutaneous Medicine and Surgery, 3, 18-23.

[32] Schor, S.L. (1980) Cell Proliferation and Migration on Collagen Substrata in Vitro. Journal of Cell Science, 41, 159175.

[33] Chen, F., Yoo, J.J. and Atala, A. (1999) Acellular Collagen Matrix as a Possible "Off the Shelf” Biomaterial for Urethral Repair. Urology, 54, 407-410. http://dx.doi.org/10.1016/S0090-4295(99)00179-X

[34] El-Kassaby, A.W., Retik, A.B., Yoo, J.J. and Atala, A. (2003) Urethral Structure Repair with an Off-the-Shelf Collagen Matrix. The Journal of Urology, 169, 170-173. http://dx.doi.org/10.1016/S0022-5347(05)64060-8 